\title{
Analysis of variation trends and causes of aerosol optical depth in Shaanxi Province using MODIS data
}

\author{
DONG ZiPeng*, YU Xing, LI XingMin \& DAI Jin \\ Meteorological Institute of Shaanxi Province, Xi'an 710014, China
}

Received April 27, 2013; accepted June 9, 2013; published online July 25, 2013

\begin{abstract}
The temporal and spatial variations and causes of aerosol optical depth (AOD) in Shaanxi Province were investigated based on the Moderate Resolution Imaging Spectroradiometer (MODIS) derived aerosol data for the period of March 2000-February 2012. The results showed that the distribution of aerosol was largely affected by topography and local economic activities. Heavy aerosol loading and increasing tendency in AOD was observed in Guanzhong, Hanzhong and Ankang basin, while a reverse tendency was revealed in most other regions. The spatial distribution of aerosol Angstrom wavelength exponent was predominantly related to vegetation coverage in Shaanxi. Airborne dust from ground is an important source of coarse mode aerosols. Vegetation improvement indicated by an increase in normalized difference vegetation index (NDVI) and a reduction in dust weather led to a gradual decrease in coarse mode AOD to the north of Qinling Mountains in Shaanxi, while anthropogenic activities led to an increase in fine mode AOD in other areas except those covered by forests. The main aerosol type gradually shifted to the urban industrial type in Shaanxi.
\end{abstract}

MODIS, aerosol optical depth, variational trend, cause analysis, Shaanxi

Citation: Dong Z P, Yu X, Li X M, et al. Analysis of variation trends and causes of aerosol optical depth in Shaanxi Province using MODIS data. Chin Sci Bull, 2013, 58: 4486-4496, doi: 10.1007/s11434-013-5991-z

Atmospheric aerosols, which generally refer to particles suspended in the atmosphere with a size ranging from 100 $\mathrm{nm}$ to tens of microns, originate mainly from anthropogenic sources such as industrial activities and fuel consumption and natural sources including sea spray, forest fires, and dust. As an important component of the atmosphere, aerosols influence the earth's climate directly by scattering and absorbing the solar and terrestrial radiations and indirectly by modifying the cloud macro- and micro-physical properties and atmospheric chemistry. Due to the short life cycle and high variability in physical and chemical characteristics, the spatial and temporal distributions of aerosols have been poorly understood [1]. Moreover, the radiative forcing of aerosols is the largest uncertainty in global climate change. Therefore, long-term observations of aerosols on the global scale are of particular importance.

To further understand the roles of aerosols in global cli-

*Corresponding author (email: dzp2003@126.com) mate change, numerous investigations on long-term trends of aerosol variation have been conducted. Kishcha et al. [1] demonstrated declining trends in aerosol optical depth (AOD) over much of the globe as determined by Moderate Resolution Imaging Spectroradiometer (MODIS) global monthly data from the Terra satellite MOD08_M3, Collection 4, during March 2000 to May 2006. Meij et al. [2] evaluated global and regional AOD trends between 2000 and 2009 by using Level 3 AOD products of MODIS and multi-angle imaging spectroradiometer (MISR) and detected generally negative trends over Europe and North America and mostly positive trends over South and East Asia. The trend indicated in East Asia is consistent with an increase in pollutant emissions through the use of fossil fuels and growth in industrial and urban activities in which changes to the $\mathrm{SO}_{2}$ emissions dominate AOD trends. Of these, $\mathrm{NO}_{x}$ emissions may become increasingly important, especially in Asia. Koukouli et al. [3] showed a negative trend in AOD over the Southern Balkan/Eastern Mediterranean region, 
where the highest annual decreasing rate is $4.09 \%$ for the summer months and the lowest $2.55 \%$ for the winter months. Dani et al. [4] observed an increasing AOD trend of $380 \mathrm{~nm}$ at $45 \%$ per decade at Pune, India, during May 1998December 2007. In addition, long-term increasing trends in Angstrom wavelength exponent (Alpha) and mean turbidity coefficients of $25.3 \%$ and $8.4 \%$ per decade is revealed respectively, which indicates that fine-mode aerosols have been increasingly added to the atmosphere over urban regions due to increases in urbanization and human activity. In general, the aforementioned aerosol trends are supported by aerosol robotic network (AERONET) ground observations, which suggest that fine-mode dominant aerosols are more prevalent at stations in or near regions with emerging economies or where slash-and-burn techniques are practiced in East Asia and South Africa, while decreasing or inconspicuous trends occur over western Europe and North America. In addition, the weighted trends of coarse-mode dominant aerosols increase and decrease over different desert regions, depending on the meteorological conditions [5].

Many investigations of AOD trends have been also conducted in China. Xia [6] investigated the variability of AOD at 79 AERONET sites and the results showed that AOD decreased significantly in North America and in Western Europe. However, AOD trends in other regions were marginal except at a few sites located in the Sahel and Saudi Arabia where AOD increased significantly. On the basis of monthly AOD measurements obtained from total ozone mapping spectrometer (TOMS) between 1980 and 2001, Hu et al. [7] observed distinct AOD increasing trends in the eastern Qinghai-Tibetan Plateau, Southwest and North China, and the middle and lower reaches of the Yangtze River but marginally decreasing trends over western and northern Xinjiang and in some regions in South China. By using the same set of data, Xie and Xia [8] demonstrated a decreasing tendency of AOD from 1980 to 1991 and a reverse tendency from 1997 to 2001 in North China. Luo et al. [9] used AOD values retrieved from direct solar radiation data of 47 stations over China between 1961 and 1990 to determine that the AOD increase over most regions was particularly rapid in the southwest, middle, and lower reaches of the Yangtze River and in the main body of the Qinghai-Tibetan Plateau, relatively slow in the northwest and northeast regions, and slightly reduced in the western region of Xinjiang and parts of Yunnan. Moreover, they determined that the decreasing trend of regional dust storm frequency may be responsible for the insignificant increase of AOD in the northwest region [10] and that an AOD increase in stations at Fuzhou, Guangzhou, Haikou, and Nanning led to a reduction in direct solar radiation [11]. Qiu and Yang [12] demonstrated an increasing tendency of AOD from 1980 to 1994 at five sites (i.e. Urumqi, Golmud, Harbin, Beijing and Zhengzhou) located in North China using the same method. Significant increase in AODs at Beijing from 1980 to 2005 was also revealed on the basis of a compilation of AERONET and historic aerosol data [13]. Duan and Mao [14] showed that the seasonal peak of AOD changed from spring to summer in the Yangtze River Delta region. The AOD in spring was significantly decreased, while that in the other three seasons increased slightly and this increase was most rapid in summer, suggesting that a gradual reduction in dust frequency may have caused an areal reduction in the AOD peak distribution in the spring and that an AOD increase in the summer may be attributed to rapid growth of the pollutants. Xin et al. [15] showed a slight increase in AOD and Alpha at the Bohai Rim of China in 2004-2010, indicating that fine-mode or secondary aerosols have gradually increased during that period. Zheng et al. [16] used monthly L3 MODIS AOD data from 2000 to 2009 and reported positive trends in annual AOD averaged over all Chinese Province-level divisions at a rate of 0.019 per decade: 17 divisions in high-emission regions of China experienced positive AOD trends, while 12 in low-emission areas showed negative trends. Guan and Li [17] also reported seasonally positive AOD trends in the central and eastern parts of China.

Shaanxi Province, located in central China, is an important hub for connecting the central, eastern, northwestern, and southwestern areas of the country. The Guanzhong lowland is its economic core and is an important area of wheat and corn production in northern China. In addition, this area is one of the three key economic zones for large-scale development in western China. The very rapid urban construction and economic development, accelerated industrialization, substantial pollutant emission by human activities, and complex terrain in this region, have resulted in high AOD [18-20], poor quality of atmospheric environment, and a serious shortage of water resources [21]. Therefore, it is necessary to investigate the spatial and temporal distribution of aerosols in this area. In this paper, MODIS C005 products are used to analyze the spatial distribution and seasonal variation of aerosols in Shaanxi to provide a better understanding of AOD trends and their causes.

\section{Data and methods}

\subsection{Data}

MODIS has supplied useful information on aerosols, clouds, moisture, and the ground surface since its launch on the Terra satellite in December 1999 [22, 23]. MODIS products are becoming increasingly important data sources for studies on the physical characteristics and radiative forcing of aerosols, and global climate change [18]. The accuracy and coherence of aerosol retrievals for its C005 version show significant improvement after several times optimization of retrieval algorithm [24-27]. The relationship between MODIS retrieved and ground-based measured AOD shows good agreement over well vegetated areas in China with more than $50 \%$ of the MODIS AODs fall within the ex- 
pected error envelope [28, 29]. What's more, AODs derived from MODIS data are somewhat more accurate than that derived from MISR and OMI in desert area [30]. It has been reported that MODIS products are highly applicable to Shaanxi Province [31-33]. Fine mode AOD (AODf) from MODIS data compare well with that observed by AERONET and can be used to quantitatively describe the AOD for fine aerosol particles. Alpha from the MODIS product can be employed for qualitative judgment of the aerosol mode [34]. Assuming the size distribution of aerosol particles fits Junge-distribution, the relationship between AOD and Alpha can be expressed as

$$
\tau_{a}(\lambda)=\beta \lambda^{-\alpha},
$$

where $\tau_{a}(\lambda)$ is the AOD at $\lambda, \beta$ is Angstrom turbidity, and $\alpha$ is Angstrom wavelength exponent inversely related to the effective radius of aerosol particles. MODIS AOD at 550 $\mathrm{nm}$ can be obtained by interpolation between AODs at 0.66 and $0.47 \mu \mathrm{m}$ with the above-mentioned formula.

The AOD data used in this study include MODIS C005 L2 data obtained from March 2000 to February 2012 with an average grid size of $0.1^{\circ} \times 0.1^{\circ}$. To maintain integrity and continuity of the data, a year was defined as the period from March to February. Ancillary data include the advanced spaceborne thermal emission and reflection radiometer (ASTER)-digital elevation model (GDEM), normalized differential vegetation index (NDVI), gross domestic product (GDP), and meteorological data. $30 \mathrm{~m}$ resolution GDEM data were obtained from the national aeronautics and space administration (NASA) warehouse inventory search tool (WIST) website (https://wist-ops.echo.nasa. gov/api/), NDVI from the atmosphere archive and distribution system (LAADS) website (http://ladsweb.nascom.nasa.gov/data/ search.html) of Goddard space flight center, and GDP from a statistic yearbook of Shaanxi Province.

\subsection{Calculation of aerosol scale height}

Generally, the distribution of aerosol extinction coefficient is exponential in the vertical direction and can be expressed as

$$
\beta_{z}=\beta_{0} \exp (-z / H)
$$

where $\beta_{0}$ and $\beta_{z}$ are extinction coefficient at the surface and at a height of $z$, respectively, and $H$ is aerosol scale height. AOD is defined as the integral of extinction coefficient in the vertical direction. AOD from $z$ to the atmospheric top $\tau_{z}$ is

$$
\begin{aligned}
\tau_{\mathrm{z}} & =\int_{z}^{\infty} \beta_{0} \exp (-z / H) \mathrm{d} z=H \beta_{0} \exp (-z / H) \\
& =\tau_{0} \exp (-z / H)
\end{aligned}
$$

where $\tau_{0}$ is AOD measured at the surface. If it is assumed that the vertical distribution of extinction coefficient is similar in a given area, the aerosol scale height $H$ for this area can be easily obtained using areal DEM and AOD.

\section{Result analyses}

\subsection{Spatial and temporal distribution of aerosols in Shaanxi Province}

AOD is closely related to the topography [18-20]. Figure 1 displays the spatial distribution of yearly average AOD (b) with the terrain (a), suggesting that a significant inverse correlation exists between them. The maximum AOD was located in Xi' an City and extended eastward to Gaoling, Lintong, and Weinan, which are located in the lowland of Guanzhong, the most developed area in the Province, less than $500 \mathrm{~m}$ above sea level. The second maximum AOD was located in the lowlands of Hanzhong and Ankang in south Shaanxi. Otherwise, AOD is significantly lower in high-altitude areas of the Qinling and Bashan mountains and north Shaanxi. These data suggest that the topography significantly affects AOD distribution. In addition, the AOD was higher in the lowland of Guanzhong than in the lowland of south Shaanxi and was markedly higher in Xi' an than in its surrounding regions, which further indicates the impact of local aerosol sources on the AOD.

Alpha is a characteristic parameter of AOD dependency on wavelength, and is inversely correlated to the effective radius of aerosol particles, that is, the smaller the Alpha value, the larger the effective radius of the aerosol particles. Figure 2 shows the significant positive correlation between the spatial distribution of NDVI and Alpha. Alpha is larger in areas of good vegetation coverage, where aerosols are fine-mode dominant while much smaller in areas with poor vegetation coverage, where aerosols are coarse-mode dominant. This result implies that dust or airborne sand from the surface is an important source of local coarse particles. In addition, the terrain and human activities have significant impacts on Alpha. It is difficult for large particles to reach higher elevations via vertical exchange within the boundary layer; therefore, dense mountain vegetation, scarcity of human activities, and lack of local emission sources of coarse particles contribute to form high Alpha values in mountains regions. Conversely, anthropogenic activities produce large amounts of fine aerosol particles in densely populated urban areas. However, airborne dust originating from traffic and construction activities in urban areas, in addition to larger particle sizes of soot aerosols produced by industrial and civil coal fuel combustion [19], cause coarse-mode aerosols to occupy larger proportions of aerosol particles, thus resulting in smaller Alpha values in urban regions than in suburban and mountainous regions. Figure 2 indicates that Alpha in the lowland of Guanzhong was significantly lower than in the surrounding areas and in south Shaanxi, with a minimum in Xi' an City. 

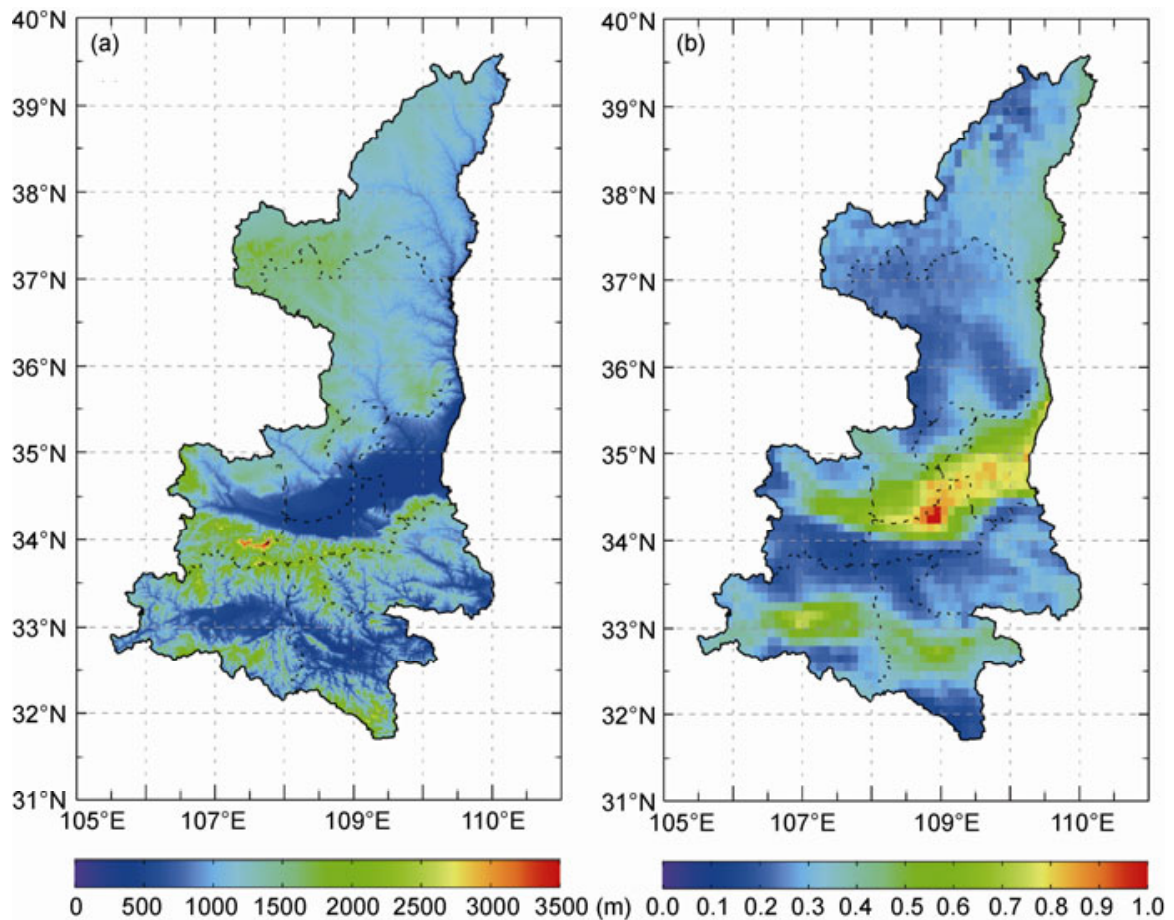

Figure 1 Spatial distribution of terrain (a) and 12-year AOD average at $550 \mathrm{~nm}$ (b) over Shaanxi.
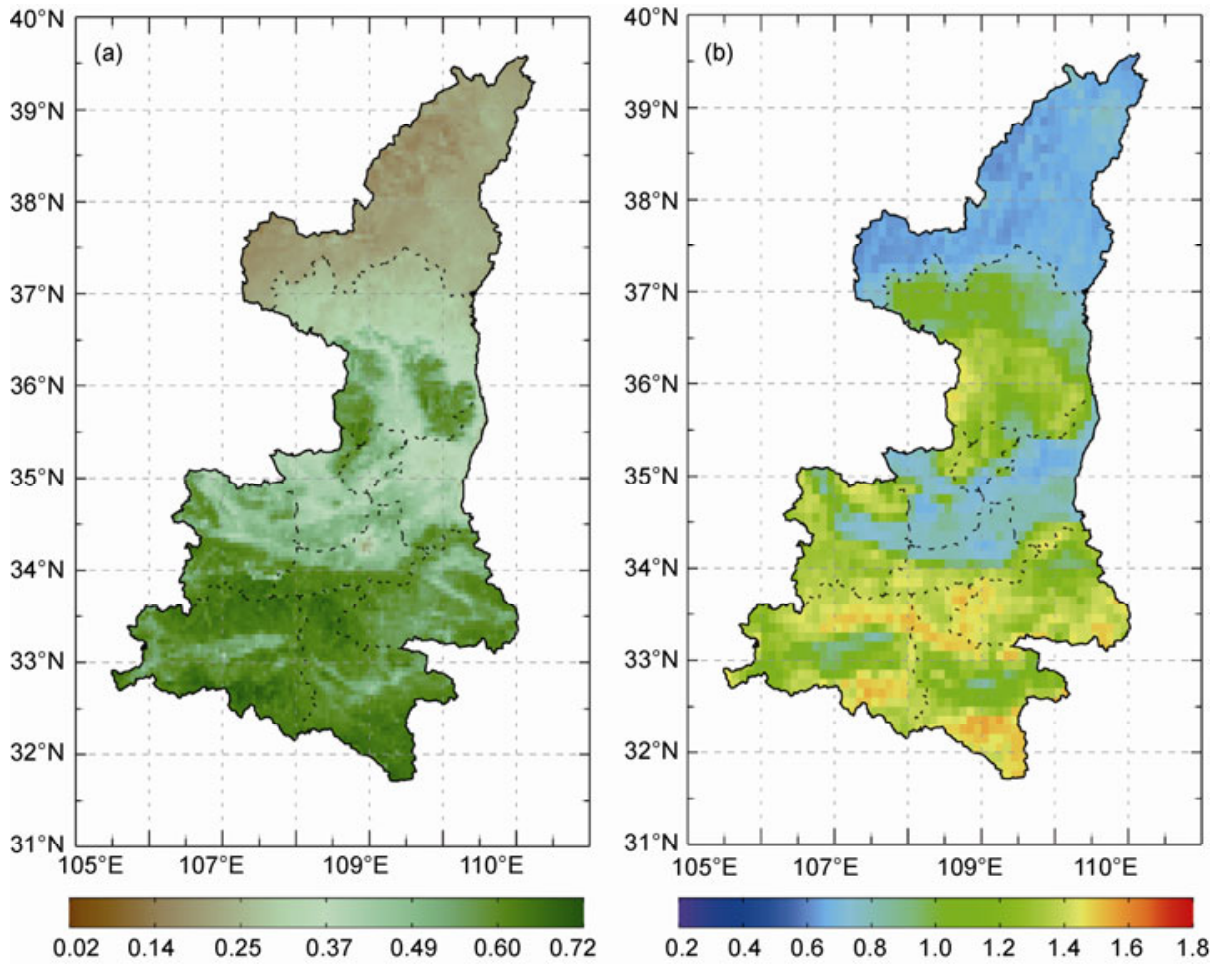

Figure 2 Spatial distribution of yearly average NDVI (a) and Alpha (b) over Shaanxi.

To identify relatively flat areas for establishing the relationship between AOD and DEM, only $0.1^{\circ} \times 0.1^{\circ}$ grids to the south of the Loess Plateau with DEM standard deviation less than 0.15 times of the average DEM value were selected to fit the AOD variation with altitude. Figure 3 shows the relationship with a remarkable exponential function from which the scale height of aerosol can be inferred as $867.7 \mathrm{~m}$. This value correlates strongly with those measured in other regions of China $[35,36]$ but is slightly lower than that in special lowland terrains of Guanzhong and south Shaanxi, which is not conducive to pollutant diffusion. AOD remained stable at altitudes higher than $1750 \mathrm{~m}$, which can be 

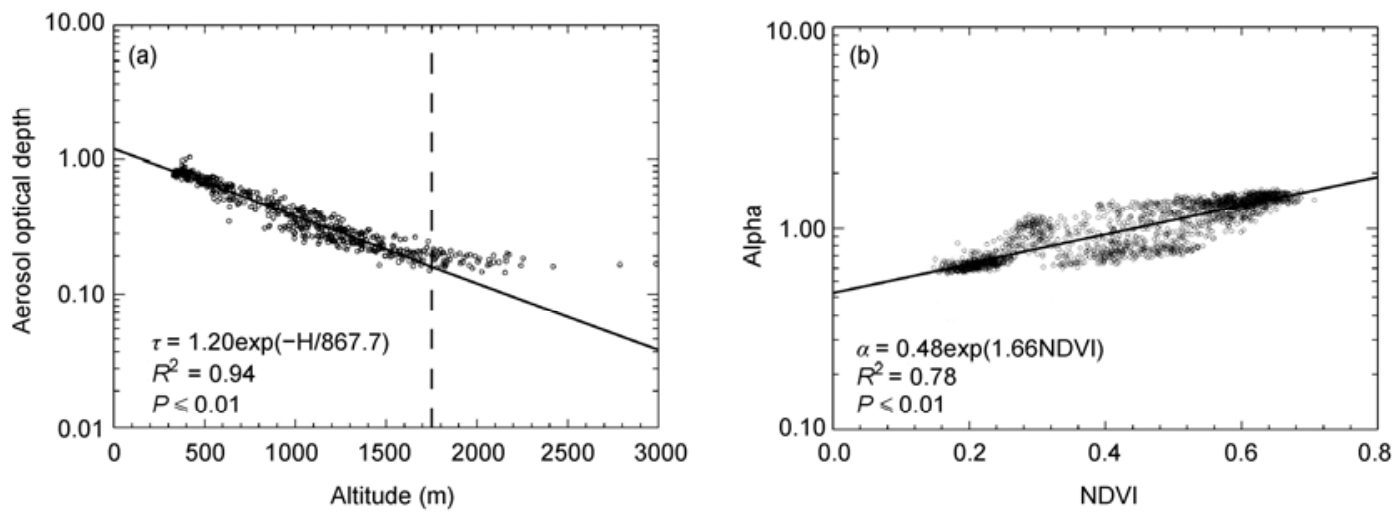

Figure 3 Relationship between AOD and altitude (a) and that between NDVI and Alpha (b) over Shaanxi.

approximated as the top of the boundary layer in Guanzhong and south Shaanxi. NDVI correlated significantly with Alpha (Figure 3), particularly for regions in which NDVI was very low $(<0.30)$ or high $(>0.65)$, which corresponds to sparsely populated areas of deserts or dense forests. Conversely, the areas with an NDVI of $0.30-0.65$ showed weaker relationships due to the impact of anthropogenic activities on Alpha.

Seasonal variations in AOD are shown in Figure 4. The maximum AOD occurred in summer in Guanzhong and in most areas of north Shaanxi because the abundant atmospheric water vapor in summer facilitated the hygroscopic growth of aerosols, which led to a significant increase in AOD [37,38]. The second maximum AOD appeared in spring due to rapidly rising temperatures and dry air that cause the soil of the thawed surface to loosen, and this enables a dust event to form under strong wind conditions. In addition, spring is the most active season for cold fronts in northwestern China due to the effects of Siberian cold and dry air masses meeting with tropical marine air masses. The strong winds behind these cold fronts provide favorable dynamic conditions for dust weather [39]; therefore, more frequent dust weather causes AOD to be higher in the spring than in autumn and winter. In most parts of Shaanxi, AOD was small with minimal variation from autumn to winter. However, the value remained higher than 0.6 in Xi' an even in these seasons. To the south of the Qinling Mountains, seasonal variations in AOD differed from those to the north with the maximum value observed in spring, followed by lower values in summer and winter and the minimum measured in autumn. In this region, AOD was mainly caused by large-scale advection such as the wide range of dust weather in the spring. The smaller values in summer and autumn were essentially caused by vertical exchange, which generally transmits lower amounts of aerosols to the summit.

\subsection{Variation trends and causes of AOD}

MODIS is capable of retrieving AODs with a great accuracy on the basis of many validations conducted in Shaanxi
Province from 2002 to 2010 [31-33]. There were 59\% to $75 \%$ of MODIS products fell within the retrieval error envelope. It provides an opportunity to obtain a quantitatively reliable aerosol loading trend in that area. Figure 5 shows spatial distribution of AOD tendency rate and its significance level P in Shaanxi Province. AOD showed a decreasing trend in most parts of the Province. Significant decreasing linear trends $(P<0.05)$ were observed in central and northern regions of Yan'an, most parts of Yulin, Baoji, and the mountain ridges of Qinling. The areas with increasing trends were mainly concentrated in the lowland of Guanzhong, Ankang and Hanzhong cities; however, these trends were not significant. The variation trends of coarse mode AOD (AODc) and fine mode AOD (AODf) were further analyzed (Figure 6). Their trends were determined to be essentially the same with an increase in the areas to the south of the Qinling Mountains and were opposite in other parts of the Province. In particular, AODf declined and AODc increased in the Qinling Mountains and in the natural forest areas of the Qiao and Huanglong mountains; the opposite was noted in other regions.

On the basis of land surface, average AOD and the significance level of AOD variation trend, 14 typical sites located over several distinct types of land surface were selected to analyze the causes of AOD trends in Shaanxi (Figure 7), including three sites (i.e. Zichang, Ansai and Yanchang) over forestland converted from farmland in the Loess Plateau, three sites (i.e. Changwu, Xunyi, and Baishui) in the transition area from the Loess Plateau to the Guanzhong basin, five urban/suburban sites (i.e. Fuping, Qianxian, Xi'an, Gaoling, and Baoji) in the Guanzhong basin, two urban/suburban sites (i.e. Ankang and Foping) and one natural forest site (i.e. Langao) in south Shaanxi, The correlations of AODc with dust weather frequency for the 14 selected sites are given in Table 1 . The yearly average AODc was larger than 0.3 for most sites, suggesting a larger amount of coarse mode particles in the atmosphere. Dust weather occurred more frequently in north Shaanxi, less in the lowland of Guanzhong, and least in south Shaanxi according to the distance from the dust source and vegetation coverage conditions. However, the maximum AODc 

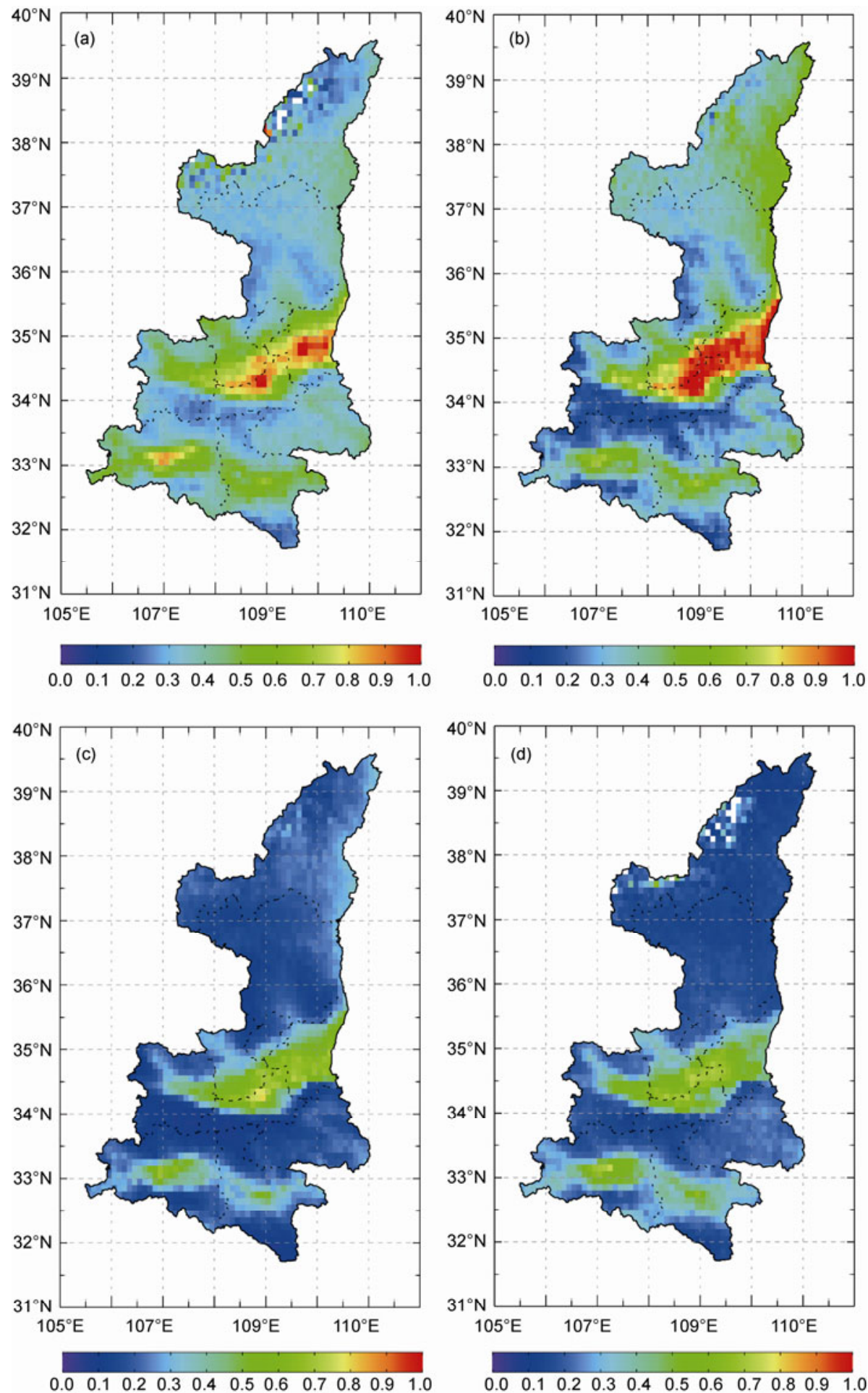

Figure 4 Seasonal distributions of average AOD over Shaanxi in spring (a), summer (b), autumn (c), and winter (d).

occurred in the lowland of Guanzhong, which conflicts with the dust frequency. This result suggests that dust originating from traffic in addition to construction activities in this area had stronger contributions than that in north Shaanxi. AODc varied for these years with a remarkable decreasing trend in north Shaanxi and a transition area from northern Shaanxi to the lowland of Guanzhong, while the value showed a slight decrease and almost no change in Guanzhong and south Shaanxi, respectively. The frequency of dust weather decreased significantly at all sites except for Xi' an, where a slight decrease was observed. The most obvious area was north Shaanxi, followed by the lowland of Guanzhong, and south Shaanxi, indicating that the National Project "Grain to Green" in north Shaanxi strongly inhibits sand and wind. 

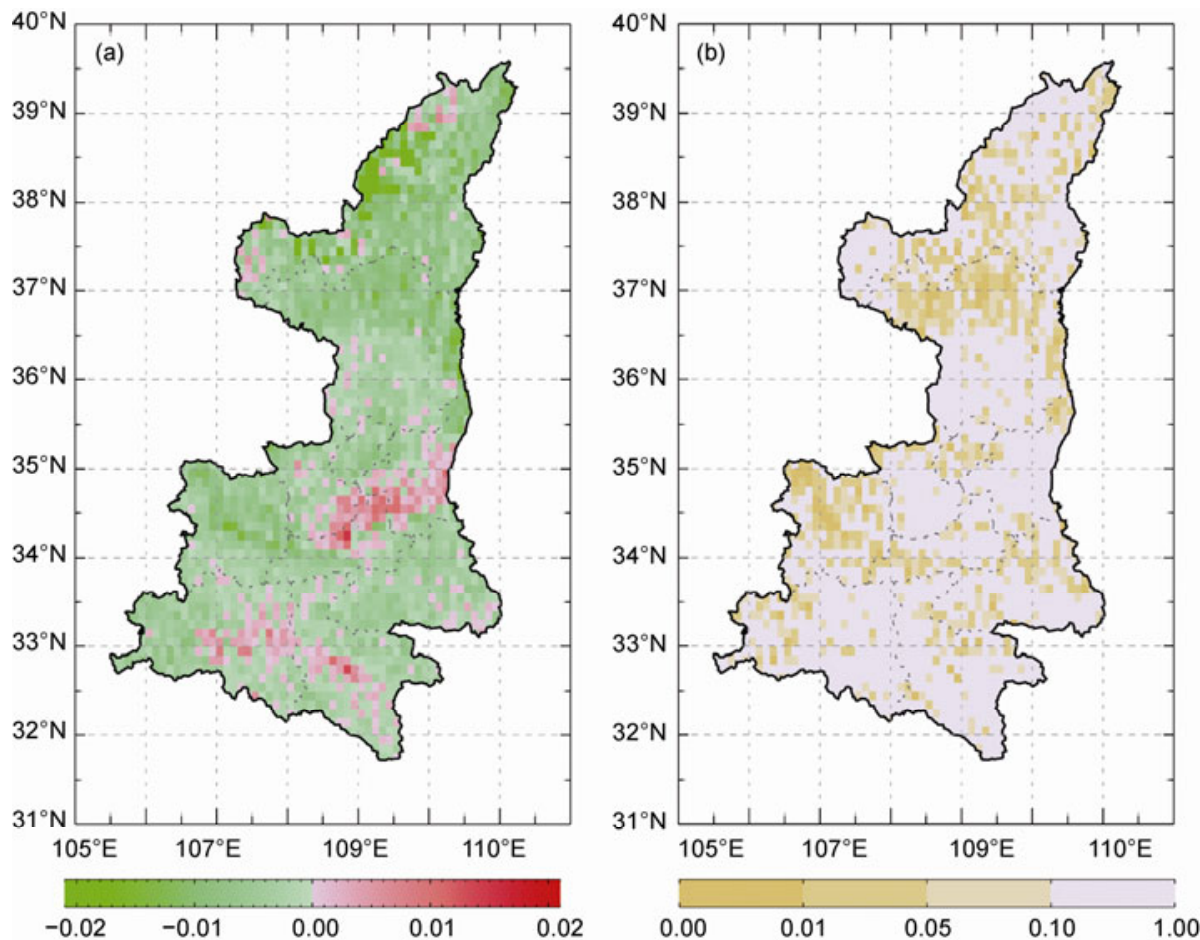

Figure 5 Spatial distributions of yearly AOD tendency rate (a) and its significance level P (b) in Shaanxi Province.
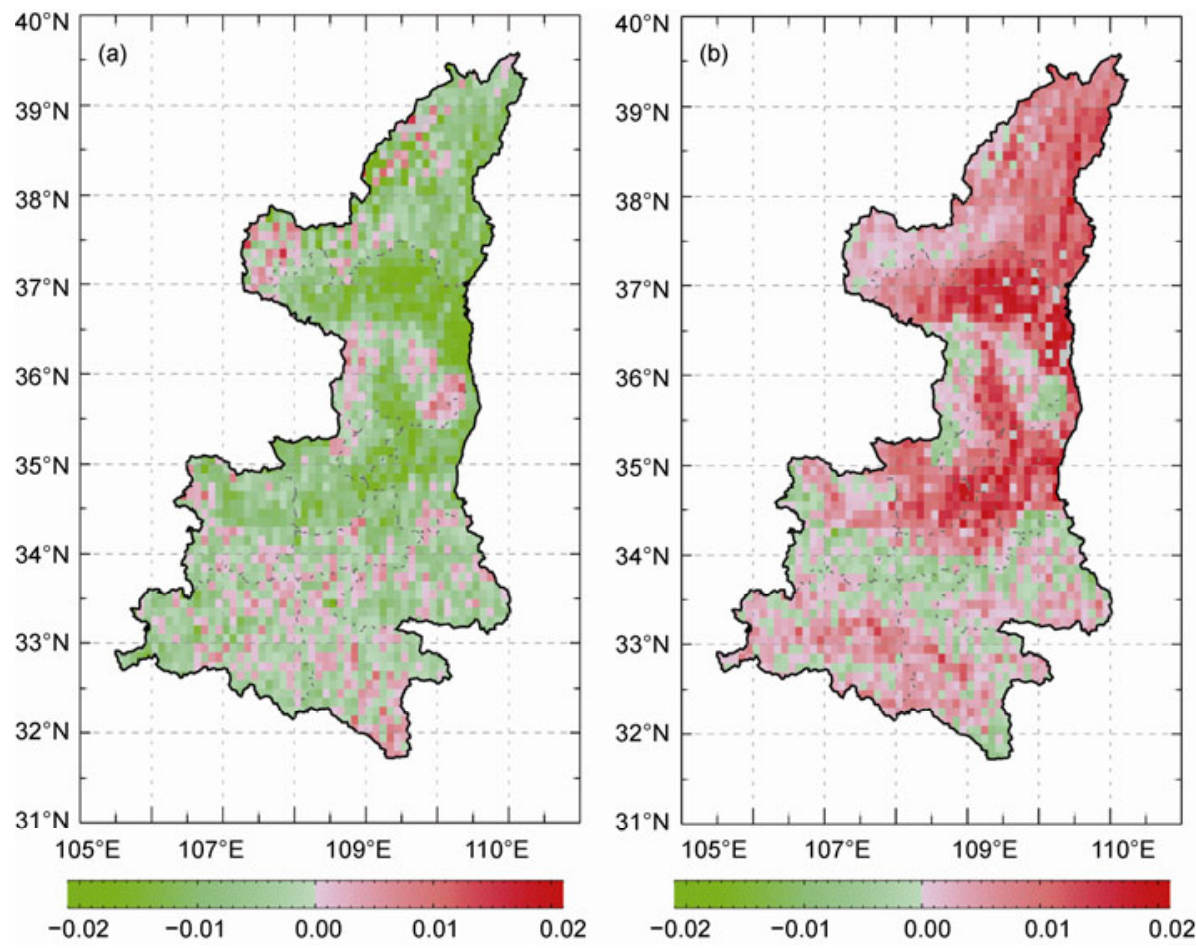

Figure 6 Spatial distributions of yearly AOD tendency rate for fine (a) and coarse (b) particles in Shaanxi Province.

Moreover, the relationship between AODc and dust weather frequency was significantly positive in north Shaanxi and in the transition area from northern Shaanxi to the lowland of Guanzhong and weak in the lowland of Guanzhong and south Shaanxi. These results suggest that only a small frac- tion of coarse mode aerosols can be attributed to dust weather and that most occur through emissions from human activities. Therefore, variations of dust weather alone cannot explain the changes in AODc in these areas.

Figure 8 further shows the relationship between NDVI 


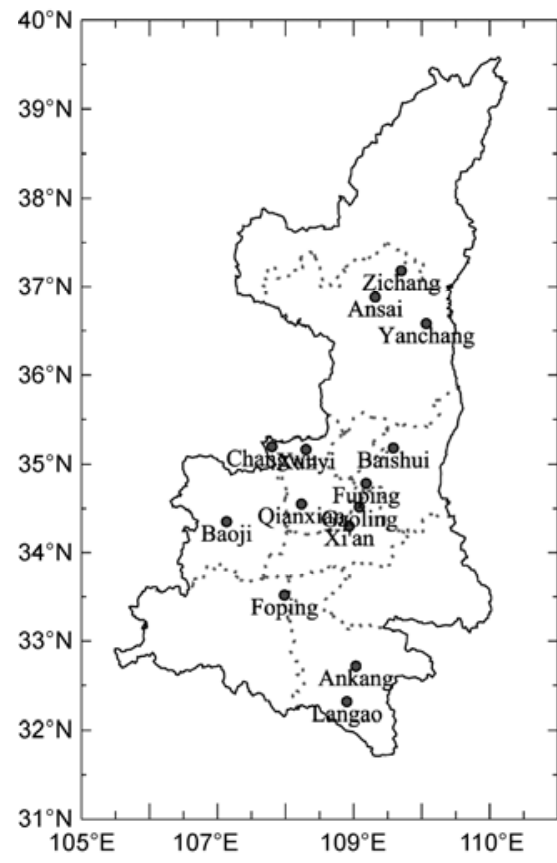

Figure 7 Locations of the 14 sites selected to analyze the causes of AOD trends.

and AODc for the four sites including Langao in the natural forest area and Zichang, Ansai, and Yanchang in the area of restored forest from farmland in the Loess Plateau whereby NDVI had a significant impact on AODc such that NDVI increased and AODc declined gradually. These results suggest that a decrease in dust weather due to improvements in vegetation cover led to a decrease in AODc.

To further understand the relationship between AOD and human activities, AOD and its components were compared with the GDP index. Figure 9 shows the yearly variation of GDP index, AODf, AOD, and Alpha for all selected sites. The trends of AODf for all sites were similar with two peaks occurring in the period between 2006 and 2007, and in 2011, a slow increase before 2007, a significant decline from 2007 to 2009, and a rapid increase after 2009. The yearly AODf variation is closely related to human economic activities, and its trend is consistent with that of the GDP index of Shaanxi Province. The declining AODf corresponds with an outbreak of the global financial crisis in 2008. The value began to increase after the economy recovered slowly in 2009. Under the indicated declining trend of AODc, the fluctuation of the total AOD, which includes AODc and AODf, depend on that of AODf, which suggests that human activities have an increasing impact on the AOD. In addition, the Alpha continued to increase for all sites, which implies that the aerosol gradually shifted to an urban industrial type in Shaanxi Province by the influence of industrialization to significantly affect local weather and climate. The spatial and temporal distribution of aerosol loadings is also closely associated with weather patterns [6]. The seasonal evolution of wind and relative humidity fields (figure omitted) for higher AOD loading in 2007 and lower AOD loading in 2009 were analyzed to understand the role of meteorological conditions in determining the aerosol distribution. Wind field at $850 \mathrm{mb}$ from NCEP reanalysis data showed that the dominant airflow to northern Shaanxi in spring is from northwestern regions in 2007 and from southeast in 2009, in addition to a drier climate in spring of 2007 shown by relative humidity field, suggesting more conducive to the formation of dust weather and a high aerosol loading. The prevailing winds in summer and autumn were southeast in both years, however, the higher humidity

Table 1 Yearly average, tendency rate (TR) of coarse mode aerosol optical depth (AODc) and frequency of dust weather (FD), and the fitting slope of AODc with FD from 2000 to 2011

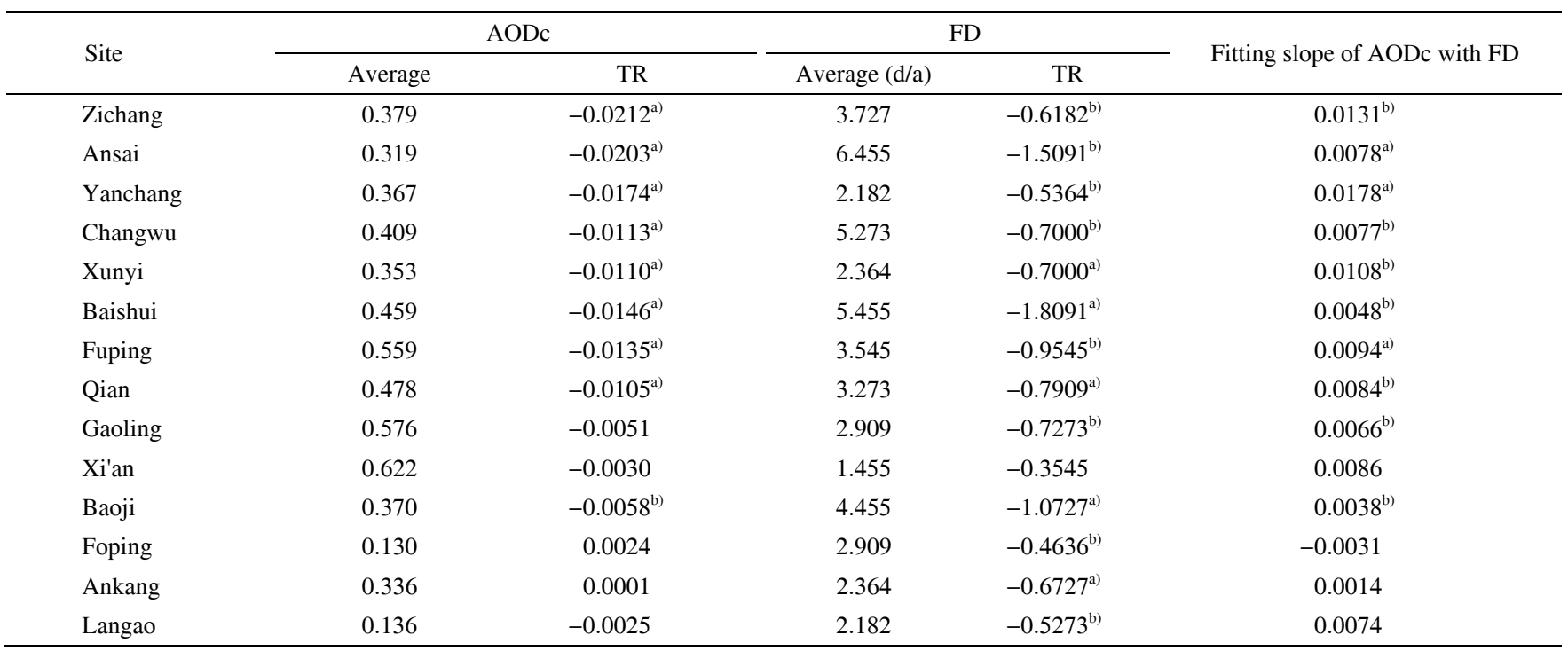

a) and b) indicate confidence levels of $99 \%$ and $95 \%$, respectively. 

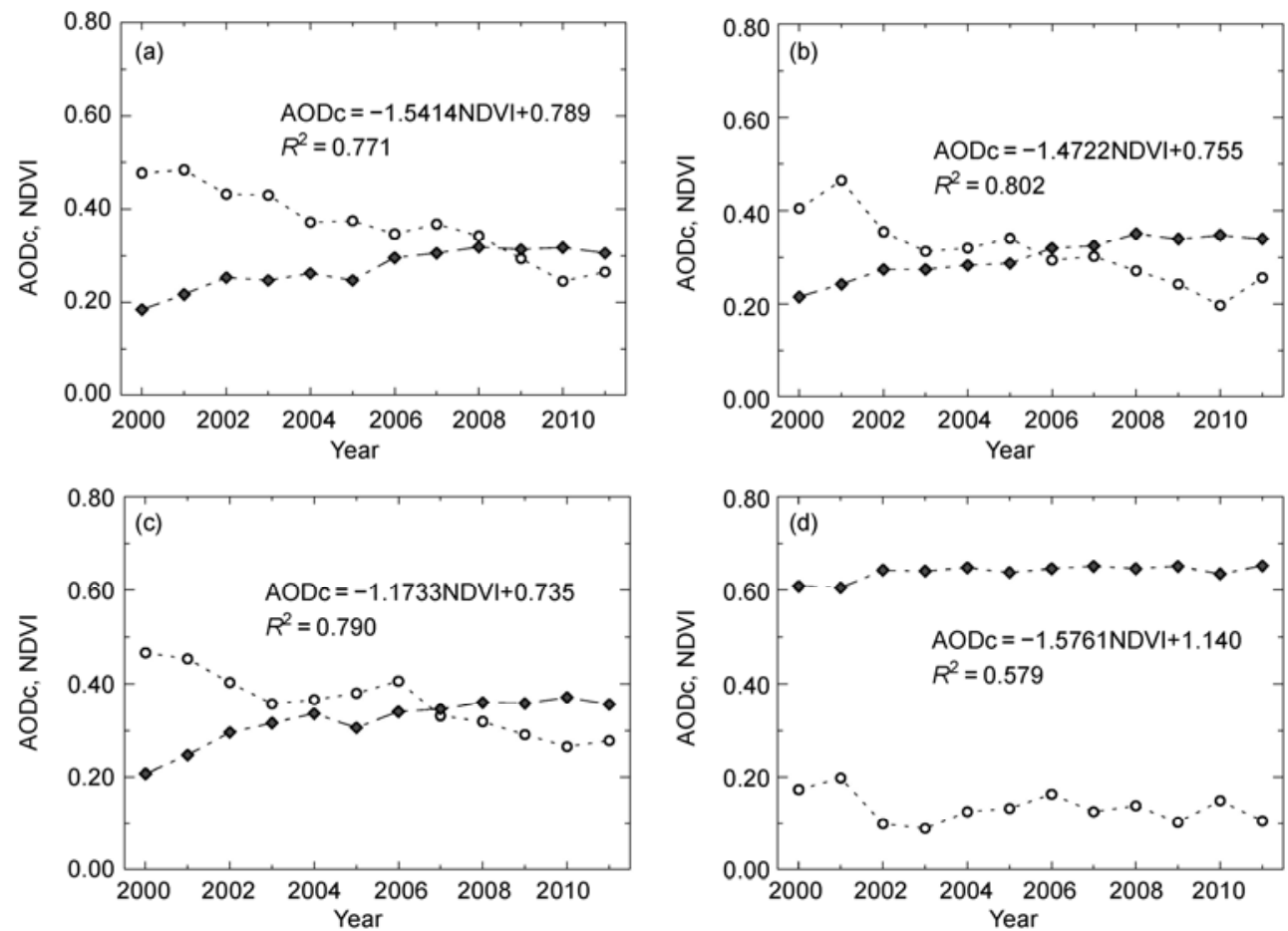

Figure 8 Yearly variation in coarse mode AODc and NDVI recorded in Zichang (a), Ansai (b), Yanchang (c), and Langao (d). AODc are denoted by open circles, and NDVI by filled diamond.
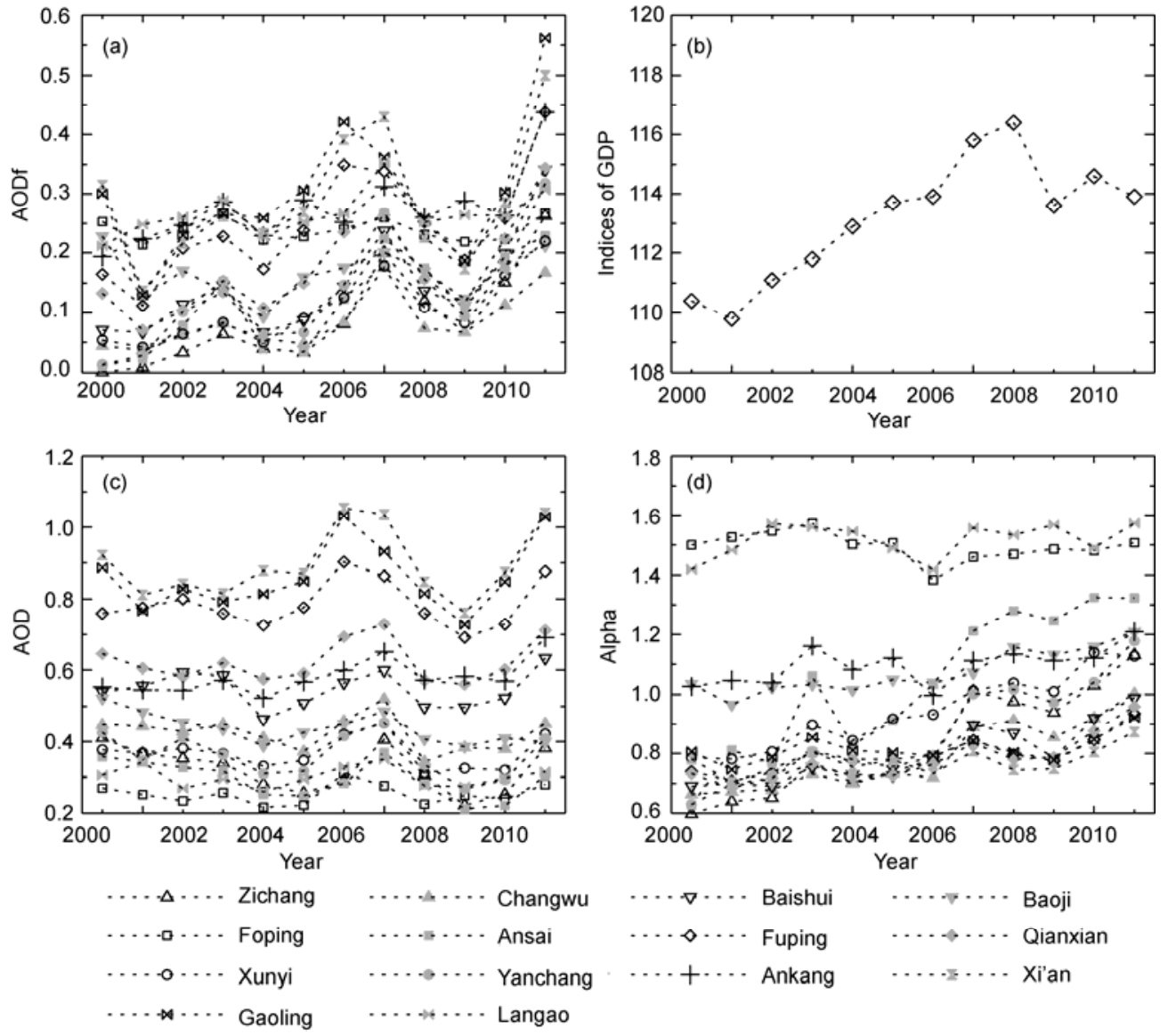

Figure 9 Time series of AODf (a), indices of GDP (b), AOD (c) and Alpha (d). 
and lower wind speed in 2007 was liable to the accumulation of pollutants and their hygroscopic growth, leading to increasing in AOD in these seasons. All these imply that yearly AOD distribution corresponds to the meteorological condition. However, the effects of human activities and change of land use are not easily excluded in such analyses, therefore, there is a need for further study on the impact of meteorological condition on the spatial and temporal distributions of aerosols.

\section{Conclusion}

The variation and distribution of AOD in Shaanxi Province presents unique regional and seasonal characteristics. Geographically affected by terrain and local sources, the maximum of AOD occurred in the three lowland regions of Guanzhong, Ankang, and Hanzhong. Seasonally, the variation of seasonally averaged AOD over the Loess Plateau and Guanzhong basin showed a single peak distribution, with the maximum value occurring in summer and minimum in winter. However, in south Shaanxi, the maximum AOD occurred in spring, the next highest AOD occurred in summer and winter, and the minimum AOD occurred in autumn. The average scale height of aerosols in Guanzhong was $867.7 \mathrm{~m}$. Changes in AOD were minimal above $1750 \mathrm{~m}$, which can be approximated as the top of the boundary layer in Shaanxi Province.

The spatial distribution of aerosol Angstrom wavelength exponent was positively related to vegetation coverage in Shaanxi Province. Surface vegetation coverage significantly influenced AODc. Sand and dust were the main sources of AODc in the Loess Plateau and also had an impact on AODc in the lowland of Guanzhong. In the most recent 12 years, the increase in NDVI and decrease in dust frequency caused a gradual decrease in AODc to the north of the Qinling Mountains, particularly in the Loess Plateau. In the lowland of Guanzhong, AODc was affected by dust and human activities, and its variation trend was less obvious. In south Shaanxi, AODc was affected mainly by human activities and showed a slight increasing trend. Anthropogenic activities caused the increase of fine mode AOD and Alpha in most areas. In addition, variation in fine mode aerosols dominated the yearly fluctuation of AOD, and the main aerosol type shifted gradually to the urban industrial type.

This work was supported by the China Special Fund for Meteorological Research in the Public Interest (GYHY201306005), the Special Climate Change Fund of China Meteorological Administration (CCSF201327) and the National Basic Research Program of China (2013CB955800). We express our gratitude to NASA for providing data of MODIS, NDVI, and ASTER DEM. Suggestions and comments by two anonymous reviewers are also greatly appreciated.

1 Kishcha P, Starobinets B, Alpert P. Latitudinal variations of cloud and aerosol optical thickness trends based on MODIS satellite data.
Geophys Res Lett, 2007, 34: L05810

2 Meij A, Pozzer A, Lelieveld J. Global and regional trends in aerosol optical depth based on remote sensing products and pollutant emission estimates between 2000 and 2009. Atmos Chem Phys Discuss, 2010, 10: 30731-30776

3 Koukouli M E, Kazadzis S, Amiridis V, et al. Signs of a negative trend in the MODIS aerosol optical depth over the Southern Balkans. Atmos Environ, 2010, 44: 1219-1228

4 Dani K K, Raj P E, Devara P C S, et al. Long-term trends and variability in measured multi-spectral aerosol optical depth over a tropical urban station in India. Int J Climatol, 2012, 32: 153-160

5 Yoon J, Hoyningen H W, Kokhanovsky A A, et al. Trend analysis of the aerosol optical thickness and angstrom exponent derived from the global AERONET spectral observations. Atmos Meas Tech Discuss, 2011, 4: 5325-5388

6 Xia X A.Variability of aerosol optical depth and Angstrom wavelength exponent derived from AERONET observations in recent decades. Environ Res Lett, 2011, 6: 044011

7 Hu T, Sun Z B, Li Z X. Features of aerosol optical depth and its relation to extreme temperatures in China during 1980-2001. Acta Oceanol Sin, 2011, 30: 33-45

8 Xie J X, Xia X A. Long-term trend in aerosol optical depth from 1980 to 2001 in north China. Particuology, 2008, 6: 106-111

9 Luo Y F, Lu D R, He Q, et al. Characteristics of atmospheric aerosol optical depth variation over China in recent 30 years (in Chinese). Chin Sci Bull, 2000, 45: 549-554

10 Luo Y F, Lu D R, Zhou X J, et al. Analyses on the spatial distribution of aerosol optical depth over china in recent 30 years (in Chinese). Chin J Atmos Sci, 2002, 26: 721-730

11 Luo Y F, Lu D R, He Q, et al. An analysis of direct solar radiation, visibility and aerosol optical depth in South China coastal area (in Chinese). Clim Environ Res, 2000, 5: 36-44

12 Qiu J H, Yang L Q.Variation characteristics of atmospheric aerosol optical depths and visibility in North China during 1980-1994. Atmos Environ, 2000, 34: 603-609

13 Xia X A, Chen H B, Goloub P, et al. A compilation of aerosol optical properties and calculation of direct radiative forcing over an urban region in northern China. J Geophys Res, 2007, 112: D12203

14 Duan J, Mao J T. Study on the distribution and variation trends of atmospheric aerosol optical depth over the Yangtze River Delta (in Chinese). Acta Sci Circle, 2007, 27: 537-543

15 Xin J Y, Wang L L, Wang Y S, et al. Trends in aerosol optical properties over the Bohai Rim in Northeast China from 2004 to 2010. Atmos Environ, 2011, 45: 6317-6325

16 Zheng X B, Zhou C X, Luo Y X, et al. Chinese province-level variations and trends in aerosol optical depth from recent 10 years of remote sensing data (in Chinese). Ecol Environ Sci, 2011, 20: 595-599

17 Guan J X, Li C C. Spatial distributions and changes of aerosol optical depth over Eastern and Central China (in Chinese). Acta Sci Nat Univ Peking, 2009, 46: 184-191

18 Li C C, Mao J T, Lau K A. Remote sensing aerosol with MODIS and the application of MODIS aerosol products (in Chinese). Acta Sci Nat Univ Peking, 2003, 39(Suppl): 108-117

19 Li C C, Mao J T, Lau K A. Characteristics of distribution and seasonal variation of aerosol optical depth in eastern China with MODIS products (in Chinese). Chin Sci Bull, 2003, 48: 2094-2100

20 Li B,Yuan H, Feng N, et al. Spatial and temporal variations of aerosol optical depth in China during the period from 2003 to 2006. Int J Remote Sens, 2010, 31: 1801-1817

21 Che H Z, Zhang X Y, Li Y, et al. Effect of urbanization on local climate in Xi' an City in recent 50 years (in Chinese). Arid Land Geog, 2006, 29: 53-58

22 King M D, Kaufman Y J, Menzel, et al. Remote sensing of cloud, aerosol, and water vapor properties from the moderate resolution imaging spectrometer (MODIS). IEEE Trans Geosci Remote Sensing, 1992, 30: 2-27

23 Barnes W L, Pagano T S, Salomonson V V. Prelaunch characteristics of the moderate resolution imaging spectroradiometer (MODIS) on EOS2AM1. IEEE Trans Geosci Remote Sensing, 1998, 36: 1088- 
1100

24 Remer L A, Kaufman Y J, Tanre D, et al. The MODIS aerosol algorithm, products, and validation. J Atmos Sci, 2005, 62: 947-973

25 Xia X A.Significant overestimation of global aerosol optical thickness by MODIS over land. Chin Sci Bull, 2006, 51: 2905-2912

26 Mi W, Li Z Q, Xia X A, et al. Evaluation of the moderate resolution imaging spectro-radiometer aerosol products at two Aerosol Robotic Network stations in China. J Geophys Res, 2007, 112: D22S08

$27 \mathrm{Li} \mathrm{Z}$, Niu F, Lee K H, et al. Validation and understanding of MODIS aerosol products using ground-based measurements from the handheld sunphotometer network in China. J Geophys Res, 2007, 112: D22S07

28 Pan L, Che H Z, Geng F H, et al. Aerosol optical properties based on ground measurements over the Chinese Yangtze Delta Region. Atmos Environ, 2010, 44: 2587-2596

29 Xie Y, Zhang Y, Xiong X X, et al. Validation of MODIS aerosol optical depth product over China using CARSNET measurements. Atmos Environ, 2011, 45: 5970-5978

30 Wu X P, Yang J, Che H Z, et al. Verification for the satellite remote sensing products of aerosol optical depth in Taklimakan Desert area (in Chinese). Clim Environ Res, 2012, 17: 149-159

31 Wang L L, Xin J Y, Wang Y S, et al. Validation of MODIS aerosol products by CSHNET over China (in Chinese). Chin Sci Bull (Chin Ver), 2007, 52: 477-486
32 Zhou C Y, Liu Q H, Tang Y, et al. Comparison between MODIS aerosol product $\mathrm{C} 004$ and $\mathrm{C} 005$ and evaluation of their applicability in the north of China. J Remote Sens, 2009, 13: 854-862

33 Wang Z, Peng Y, Che H Z, et al. Analyses on spatial and temporal characteristics of AOD in Guanzhong region of Shaanxi Province using long term MODIS data. Plateau Meteor, 2013, 32: 234-242

34 Wang H B, Zhang L, Liu R J, et al. Comparison and assessment of the MODIS C005 and C004 aerosol products over China (in Chinese). Plateau Meteorol, 2011, 30: 772-783

35 Han Y, Rao R Z, Wang Y J. Multi-wavelength spectral aerosol scale height in inshore in contrast with that in inland (in Chinese). Spectrosc Spect Anal, 2009, 29: 33-37

36 Fan W, Han Y, Wang Y, et al. Analysis on aerosol scale height measured at inland and cosatal zone (in Chinese). Infrared Laser Eng, 2006, 35: 532-535

37 Li Z Q, Xia X A, Maureen C, et al. Aerosol optical properties and their radiative effects in northern China. J Geophys Res, 2007, 112: D22S01

38 Xia X A, Li Z Q, Brent H, et al. Aerosol optical properties and radiative effects in the Yangtze Delta region of China. J Geophys Res, 2007, 112: D22S12

39 Zhang K, Gao H W. Research on source and sink of East Asia's sand-dust aerosols (in Chinese). J Safety Environ, 2003, 3: 7-12

Open Access This article is distributed under the terms of the Creative Commons Attribution License which permits any use, distribution, and reproduction in any medium, provided the original author(s) and source are credited. 